\title{
Chapter 10 \\ Pathogens of Vertebrate Animals as Invasive Species: Insights from South Africa
}

\author{
Lesley van Helden (D, Paul D. van Helden $D^{D}$, and Christina Meiring
}

\begin{abstract}
The study of disease organisms as invasive alien species has not received a great deal of attention in the field of invasion science. Introduced pathogens can have profound effects on living organisms, the ecosystems that they inhabit, and the economies that the ecosystems support. In this chapter, we use case studies of introduced diseases of domestic and wild animals (canine rabies, bovine tuberculosis, and rinderpest) and humans (smallpox, measles and human immunodeficiency virus, HIV) to illustrate the kinds of effects that these pathogens can have. The most dramatic impact to date was that of rinderpest, which caused the death of millions of cattle, and practically annihilated certain forms of wildlife from large parts of southern Africa. This in turn impacted severely on the region's economy, and resulted in large-scale changes to the structure and dynamics of ecosystems. Rinderpest has been eradicated globally, but both canine rabies and bovine tuberculosis remain, and ongoing vigilance and management will be required to contain them. Of the human diseases, smallpox has also been eradicated globally, but the effect of the disease, introduced by European colonists, was devastating. In the early 1700s, a large proportion (up to $90 \%$ in some communities) of the indigenous Khoekhoe people died, destroying their culture and way of life, and leaving the few survivors to be recruited as farm labourers. HIV, first detected in South Africa in 1982 has also had substantial impacts and antiretroviral treatment alone currently costs the government ZAR 66.4 billion annually. We also include West Nile Virus and African Swine Fever as examples of diseases that originated in Africa, and that may yet become globally destructive. We predict that new diseases will emerge as humans continue to expand their range into wild areas, and as trade volumes increase.
\end{abstract}

\footnotetext{
L. van Helden

Department of Agriculture, Western Cape Veterinary Services, Cape Town, South Africa

P. D. van Helden $(\bowtie) \cdot$ C. Meiring

DSI-NRF Centre of Excellence for Biomedical Tuberculosis Research, Faculty of Medicine and Health Sciences, Stellenbosch University, Stellenbosch, South Africa
}

South African Medical Research Council Centre for Tuberculosis Research, Faculty of Medicine and Health Sciences, Stellenbosch University, Stellenbosch, South Africa e-mail:pvh@sun.ac.za

B. W. van Wilgen et al. (eds.), Biological Invasions in South Africa, Invading

Nature - Springer Series in Invasion Ecology 14,

https://doi.org/10.1007/978-3-030-32394-3_10 


\subsection{Introduction}

The fortunes of Homo sapiens, once a small insignificant population of a mediumsized mammal, changed fundamentally with the domestication of animals and cultivation of crops. These transitions kick-started massive population growth and increased further spread of humans around the world (Bocquet-Appel 2011; MacHugh et al. 2017). Human migration often went hand-in-hand with the migration of domesticated animals, and today it is estimated that there are globally approximately 7 billion humans, a billion sheep, a billion pigs, more than a billion cattle, 25 billion chickens, and millions of horses and donkeys (Wolfe et al. 2007; Harari 2015). These animals have been selectively bred for traits that humans found desirable e.g., milk, meat, eggs or wool production, for transport, and to serve as draught animals. This approach has resulted in decreased genetic diversity across these domestic species, which often leads to less resilience and greater vulnerability to pathogens (Gunderson et al. 1995). In the context of what is discussed below, this has enormous relevance to these species and others as hosts of infectious diseases.

A species is never introduced to a new area alone. They are in fact biological packages, because many microbes and viruses inhabit the larger species that act as their hosts. The movement of animals from place to place, therefore, implies the movement of all microscopic passengers that they are hosting. Some of these microbes are necessary for the survival of the animal; for instance, microorganisms in the gut of ruminants allow their hosts to digest their cellulose-rich food, while others are commensals or pathogens (Bergmann 2017).

The expansion of these populations has meant that the number of hosts for diseases of these species and their relatives has expanded massively along with exposure to new diseases from invasion of wildlands and subjugation of these for anthropological use (Tilman and Lehman 2001). This has meant close contact between humans, their domestic stock and wildlife (Acevedo-Whitehouse and Duffus 2009). The interface between these is an ideal venue for transmission of infectious diseases in many directions (Deem et al. 2001; Pearce-Duvet 2006). We can envisage transmission from wildlife to livestock, or from stock to wildlife, or humans to livestock (anthropozoonotic) and then wildlife, or vice versa, i.e. animals to humans (zoonotic).

Since parasites generally cause harm to their hosts, the infectious diseases we refer to here can for practical purposes be considered parasites. The effects of parasites in an ecosystem are diverse, as described by Hatcher et al. (2012). The most obvious effect is the direct harm caused by parasites to their hosts. Individual hosts can be killed, or their ability to survive and reproduce otherwise directly reduced, which in turn reduces population numbers. Individuals infected by a parasite may also show a change in behaviour. A combination of these effects can change the social structure and ecology of the affected population. A disease could even cause the extinction of a particularly vulnerable species. Infectious disease has been recorded as contributing to the demise of $4 \%$ of extinct species, and the critically endangered status of $8 \%$ of species classified as such by the International 
Union for Conservation of Nature (IUCN). Significant impact on a species is more likely when a pathogen is evolutionarily novel to a susceptible host species, which most invasive diseases are. Indirect harm is also an important effect, as one host species may act as a parasite reservoir for another more vulnerable species (Castro and Bolker 2005; Gerber et al. 2005). A quarter of the IUCN's "world's worst" invasive alien species are associated with the spread of wildlife diseases with negative environmental effects (Hatcher et al. 2012). Conversely, when population numbers of predators or competing species are reduced by parasites, it is to the benefit of other species that can increase in number due to reduced pressure. A combination of the above effects can subsequently cause vegetation and landscape changes in an area invaded by a parasite. However, it is often extremely difficult to predict or assess what damage is occurring. This is because the disease may be a slowly progressing type, leaving the animal enough time to reproduce, so that population effects may not manifest, or will manifest only over a long period. It is clear, however, that the introduction of a parasite into an ecosystem can have wideranging effects comparable to the introduction of any other invasive species.

South Africa is known for its unique biodiversity, and as one of the regions where certain ecosystems and populations of wildlife species are conserved and protected. Diversity itself can act as a buffer against threats such as infectious disease, although there is also the potential for large-scale disease spread where swaths of similar species exist together. It is therefore evident from the effects discussed above that invasive diseases could have a major impact in our region. In fact, invasive diseases have, as we will show, had a substantial impact on the ecology, economy and people of South Africa. However, it is important not to lose sight of the fact that disease knows no borders, and should ideally also be considered in a multiscale context.

The introduction of almost any pathogen into a previously naïve ecosystem is easily facilitated by the increasing trend of international and local human and animal or animal product movement. The rate of spread for many pathogens would be partially a function of this travel, and may be slow should travel or trade become restricted in future. It is highly likely that many novel pathogens have been introduced, even repeatedly, into South Africa, but did not invade. For a pathogen to progress from introduction to epidemic, the right conditions must be present. Firstly, susceptible host species must be present in the new ecosystem. Then, sufficient quantities of the pathogen must be excreted by an infected host for a sufficient time, and in an appropriate manner, to facilitate transmission to naïve hosts. For this to happen, there must be a large enough host population with adequate contact rates between individuals. Further advantages are experienced by adaptable pathogens that can evolve to infect multiple host species (Jones 2007).

A pathogen that successfully invades in a new geographic area may progress from causing an outbreak to establishing itself permanently. In epidemiology, a disease that is maintained in a certain population without needing to be re-introduced is known as endemic (Centers for Disease Control and Prevention 2012). One may assume that a high population of susceptible hosts and a high transmission rate would increase the likelihood of an invasive disease becoming endemic. However, highly virulent pathogens which produce many copies of themselves for 
transmission to new hosts tend to cause severe disease and kill their hosts quickly (Jones 2007). Using the analogy of an uncontrolled wild-fire, large, rapid outbreaks of these diseases consume all the available fuel and then die out. A disease is thus more likely to become endemic if it can employ alternative transmission or pathophysiological strategies. For instance, a chronic disease that can be transmitted by its host for a long period before causing the host's death may be able to infect the same number of hosts as a highly virulent disease, by doing so over a longer time and maintaining host population levels by causing fewer mortalities. This is not to say that a highly virulent disease cannot become endemic, as this is possible if there are barriers to rapid transmission of the disease. For instance, in arid habitats where there is a lower density of susceptible hosts, rabies transmission is stalled and the infection circulates at a very low level until a threshold is reached, either by an increase in population size, or by an individual moving out of the area and taking the pathogen to a new adjacent habitat with a large enough susceptible population (Swanepoel 1995). Other diseases may increase their likelihood of becoming endemic by infecting an asymptomatic, reservoir species or by utilising an arthropod vector, such as ticks or mosquitoes, for transmission.

While humans are most often directly or indirectly responsible for introducing invasive diseases, they also have the unique power to prevent or limit invasion by instituting control measures that could stop an outbreak from happening, stop the spread of an outbreak, or stop a new disease from becoming endemic. The diseases discussed in this chapter illustrate various combinations of the above concepts. Our discussion is limited to pathogenic bacteria and viruses, as it is not possible to cover the full range of potential pathogens. However, the reader should be aware that the other microbes, such as protozoa, fungi and metazoa, are also extremely important. In this chapter, we do not consider factors such as virulence and the interplay between invasive and dangerous or pathogenic parasites compared to dangerous but non-invasive agents, or invasive but not dangerous agents, since that would require lengthy discourse on its own.

\subsection{Animal Diseases}

\subsubsection{Canine Rabies}

Rabies is a viral disease of mammals that is almost invariably fatal once clinical signs become apparent (Franka and Rupprecht 2011). Transmission is through infected body fluids introduced through a bite or contact with mucous membranes, after which the virus spreads along the nervous system to the brain. As the disease develops it causes brain inflammation, abnormal behaviour and ultimately death through generalised muscle paralysis or seizures (Murphy 1977; Koyuncu et al. 2013).

Sporadic, unconfirmed cases of rabies in dogs were reported from South Africa between 1772 and 1861, though several travellers during that time remarked that the 
disease seemed to be absent in dogs in South Africa (Swanepoel 1995). We believe currently that this is due to a rabies biotype adapted to the Yellow Mongoose (Cynictis penicillata) that has existed in South Africa since before written history. Mongoose rabies was confirmed after years of anecdotal evidence when two children were bitten by a Yellow Mongoose in 1928 and subsequently died of rabies (Herzenberg 1928). Rabies was thereafter confirmed to be endemic in most of the country, excluding the areas where Yellow Mongooses were not present. The virus is maintained in the mongoose population, and occasionally affects other species of animals that come into contact with a rabid mongoose, but has not shown itself capable of establishing and maintaining itself in populations of other species (Swanepoel 1995).

The first time canine rabies was confirmed in South Africa was during an outbreak in Port Elizabeth in 1893; traced to an Airedale terrier imported from England a year earlier (Hutcheon 1984) (Fig. 10.1). The outbreak was controlled by killing stray dogs, and imposing restrictions on owned dogs to prevent biting, after which there were no reports of rabies spreading further or of involvement of wildlife species. Canine rabies did not feature again until it appeared in Namibia and Botswana in the 1940s, after spreading southwards from Angola and Zambia (Courtin et al. 2000). By 1950, it had spread into the then Northern Transvaal and

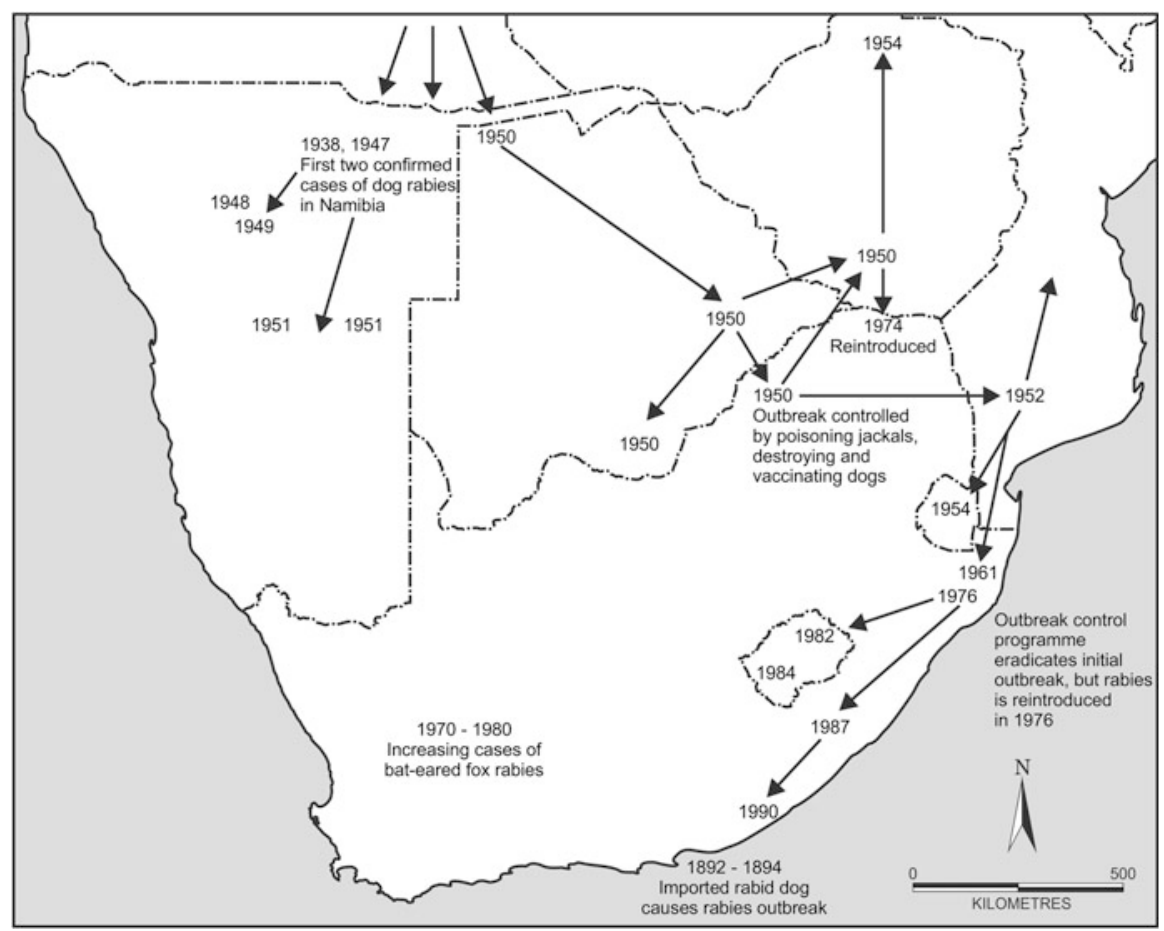

Fig. 10.1 History of rabies introduction into South Africa 
Zimbabwe (Mansvelt 1956). Dog destruction and vaccination campaigns in South Africa were unsuccessful in eradicating the disease and the virus established itself in the local dog population, causing a low number of sporadic cases in dogs in the years that followed. The infection also spilled over into Black-backed Jackals (Canis mesomelas) and cattle in the area, resulting in attempts to control the disease by poisoning 3900 jackals between 1951 and 1953 (Mansvelt 1956). There was subsequently no evidence that the virus had become established in the wildlife population. It is possible that this was because poisoning after the outbreak was rapid enough to prevent establishment of the disease in the jackal population.

However, rabies was probably reintroduced near Messina (now Musina), causing a large outbreak in the 1970s (Fig. 10.1). It was quickly realised that further attempts to control the outbreak by poisoning of jackals were futile. Once rabies becomes endemic in a population, culling strategies for control are unsuccessful, as population numbers are able to increase too quickly after culling (Swanepoel 1995). The focus on control was therefore shifted to the vaccination of dogs in the area, an approach which has been used ever since considering that dog and jackal rabies remains a problem in the area to this day. The virus spread to Mozambique by 1952 and from there to Swaziland, KwaZulu-Natal and the Eastern Cape. Sporadic cases of rabies were seen in South African Bat-eared Foxes (Otocyon megalotis) from 1955 , but case numbers rapidly increased in the 1970s when the virus apparently spread to the Northern and Western Cape (Swanepoel 1995).

Molecular analysis of rabies viruses in South Africa shows that jackals and bat-eared foxes have become maintenance hosts for their own biotypes of canid rabies (Sabeta et al. 2007). Biotypes from dogs, jackals and bat-eared foxes are more closely related to each other and to rabies biotypes from Europe than mongoose rabies, which is distantly related to both the South African canine and European biotypes (von Teichman et al. 1995; Coetzee and Nel 2007). This indicates that jackal and bat-eared fox biotypes share a common lineage with introduced dog rabies, while mongoose rabies evolved separately and is much older in South Africa.

Jackals and bat-eared foxes both have characteristics that have enabled the canid rabies virus to establish itself in their populations. For instance, bat-eared foxes are highly sociable, have overlapping territories and often share dens with other family groups of bat-eared foxes and even other species. They live in close contact, sleeping close together and often engaging in mutual grooming that involves licking of each other's faces (Nel 1993). Rabies is therefore transmitted easily by providing many opportunities for bat-eared foxes to encounter other potentially rabid animals as well as infect each other through contact with saliva. Rabies in South African wildlife appears to be seasonal, based on increased contact between animals of the same species in times of mating or dispersal of young animals to find their own territories (Swanepoel 1995). However, other effects such as climate change and drought can influence this. In the Swartland area of the Western Cape, bat-eared fox numbers fluctuate vastly from year to year, with all bat-eared foxes in an area seeming to suddenly disappear, only for the population to recover within a few years (J. van Deventer, pers. comm. 2016). Whether or not these population crashes are caused by rabies is unknown. However, this seems likely given that in areas in which the 
disease has become endemic in South Africa, the observed pattern has been that of a large initial outbreak, followed by a period of several years in which little disease is observed. Once the susceptible population is restored in that area to a density that facilitates disease transmission, secondary outbreaks of the disease are seen with this cycle repeating every few years (Swanepoel 1995).

Infected wild carnivore populations can cause spillover of rabies into other species. Sporadic cases are reported every year affecting several wildlife species in South Africa, including grey duikers, aardwolfs, meerkats, polecats and Cape foxes (Department of Agriculture, Forestry and Fisheries 2018) (Fig. 10.2). However, the most dramatic example of a rabies outbreak in a wildlife population occurred in the 1970s in Namibia. An increase in jackal rabies was noticed shortly before a largescale outbreak of rabies caused the deaths of 30-50,000 Tragelaphus strepsiceros (Greater Kudu), approximately $20 \%$ of the kudu population at the time, over the next few years. When isolated and sequenced, the virus was found to be a jackal biotype (Mansfield et al. 2006), but had apparently developed the ability to be transmitted horizontally between kudu (Scott et al. 2013). At the time of the outbreak, there were unusually large numbers of kudu in Namibia, since they were highly prized for hunting and, as a result, many game farmers had increased their numbers by

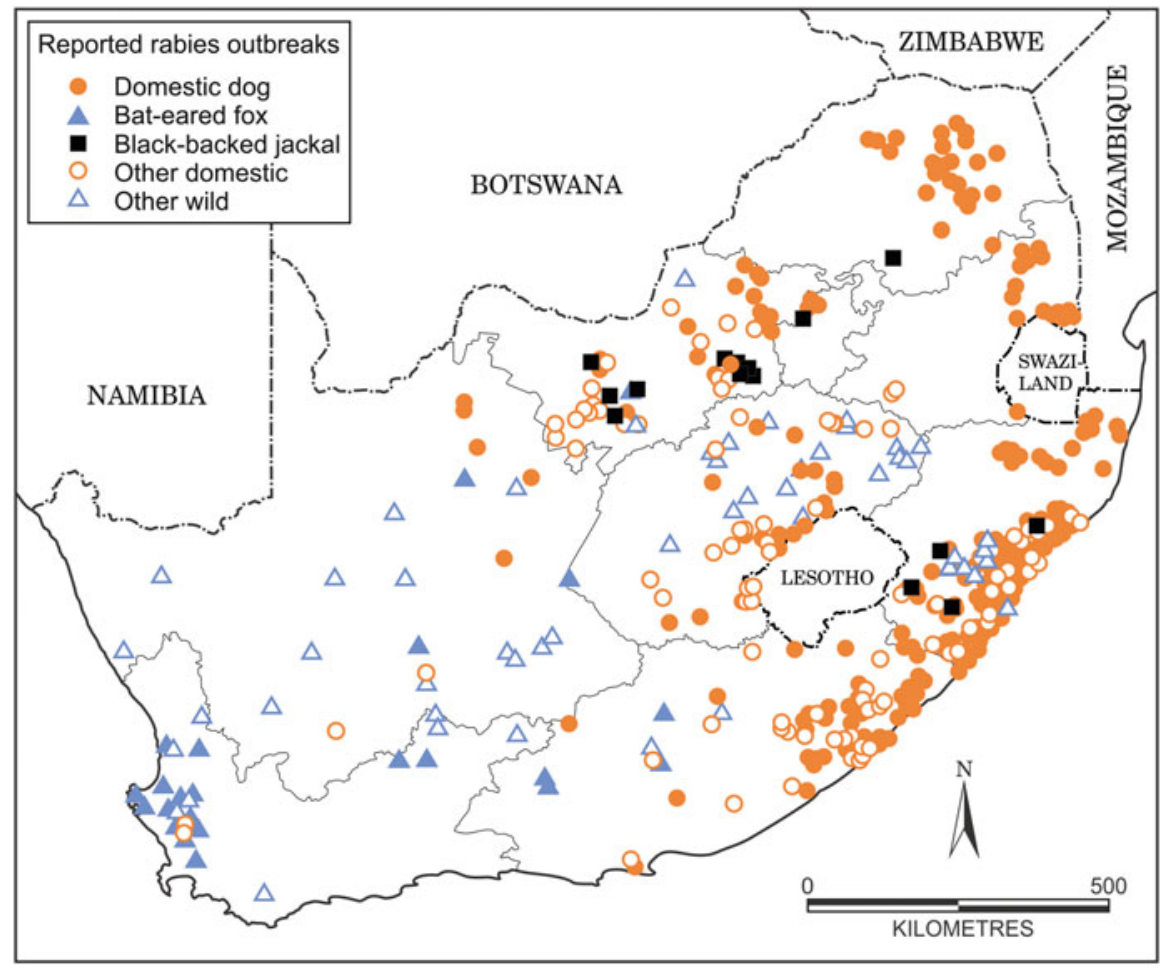

Fig. 10.2 Reported rabies outbreaks 2017-2018 (Data obtained from the Department of Agriculture, Forestry and Fisheries (DAFF), 2018) 
controlling their natural predators. In addition, overgrazing by domestic livestock combined with above-average rainfall had resulted in severe bush encroachment that favoured kudu, as they are browsers. Water provision in the form of windmills and farm dams in a traditionally arid country where water is limited are also important in kudu population dynamics and dispersal. Kudu are social animals, often browsing close together, grooming each other and grouping together and dispersing with the seasons. A rabid kudu produces large quantities of saliva, and due to their habits of feeding from thorn trees, kudu often have injuries in their mouths: an easy route of entry for the rabies virus. The combination of these factors resulted in rabies causing very high mortalities in the kudu population. Several smaller outbreaks of rabies in Namibian kudu have occurred in the years following the initial large outbreak. Molecular analysis of these rabies viruses shows that kudu are capable of maintaining epidemiological cycles of rabies within their species; this is an interesting example of how a pathogen adapts to and becomes endemic in a population (Mansfield et al. 2006).

The high burden of rabies virus during the outbreak in kudu resulted in spillover of rabies back to carnivores, including bat-eared foxes, jackals and lions in Etosha National Park in Namibia (Berry 1993). Large carnivores in Hwange and Kruger National Park in Zimbabwe and South Africa, respectively, have never been affected by rabies in the same manner when outbreaks occurred adjacent to these parks. A possible explanation for this is the higher carnivore species diversity in the latter two parks, which prevents the population of any one carnivore species from becoming particularly high. Due to its arid environment, Etosha National Park has a lower species diversity and therefore less intraspecific competition, which may facilitate rabies spread within infected species (Foggin 1988; Swanepoel 1995).

Rabies spillover in South Africa has also added a significant threat to an already endangered species. The IUCN estimates the total worldwide population of African Wild Dogs (Lycaon pictus) to be 6600 adults, and declining (Woodroffe and SilleroZubiri 2012). Current threats to wild dogs include habitat fragmentation and subsequent competition with other predators and conflict with humans (Woodroffe and Sillero-Zubiri 2012). In 1997, just 2 years after their reintroduction into the area, an outbreak of canid-biotype rabies decimated a pack of African wild dogs in Madikwe Game Reserve. Of the pack of 27, only three survived (Hofmeyr et al. 2000). A second outbreak in 2000 killed 10 of 12 pups, but the five adults in the pack survived thanks to individual rabies vaccination that had been given to the wild dogs in the park after the first outbreak (Hofmeyr et al. 2004). Similarly, in the Bale Mountains of Ethiopia, the endangered Canis simensis (Ethiopian Wolf) is under severe threat from rabies circulating in sympatric domestic dogs (Randall et al. 2004; Aguirre 2009).

The example of rabies in South Africa shows how a new strain of a previously existing disease can have radically different effects when introduced to a new area with a diverse potential host spectrum. It also shows that for a disease to become established and invasive requires more than just introduction, especially if control measures are used. In the case of rabies, repeated introductions were required before the disease established itself in wild South African canids and became endemic. This 
process is still happening, as repeated contacts with a new species may be leading to the virus establishing itself in new maintenance hosts, as was seen in the Namibian kudu. Rabies spillover to vulnerable populations, such as those of lions and African wild dogs, provides a good example of indirect species competition by one species acting as a disease reservoir for another. Lastly, rabies provides an example of the indirect damage to wildlife by the previous control measures implemented by humans to control the disease.

\subsubsection{Bovine Tuberculosis}

Bovine tuberculosis (BTB) caused by Mycobacterium bovis, has existed in European cattle for centuries. It is a chronic, slow-progressing disease that can affect most mammals, causing emaciation and eventual death (Morris et al. 1994; Rodwell et al. 2001a; De Vos et al. 2001). Transmission between individuals occurs as a result of contact with infected body fluids, usually through aerosol inhalation. It spread from the Netherlands and the UK to many parts of the world that were colonised, including South Africa, to which European breeds of cattle were brought in the late eighteenth century (Huchzermeyer et al. 1994). BTB was first recorded in cattle in South Africa in 1880 (Hutcheon 1880) and has existed ever since in livestock at a prevalence kept low by state testing and eradication schemes. Sporadic cases of BTB in wildlife were recorded since 1928 (Renwick et al. 2007), but the disease did not appear to be established in any wildlife populations until it was detected in Syncerus caffer (African Buffalo) in Hluhluwe-iMfolozi Park (HiP) in 1986 (Michel et al. 2006) and the southern part of Kruger National Park (KNP) in 1990 (Bengis et al. 1996; de Garine-Wichatitsky et al. 2010; DAFF 2013). In both cases, the source of infection is believed to be from the interaction between buffalo and infected cattle surrounding the parks. In the 1950s and 1960s, buffalo were frequently observed grazing together with cattle adjacent to the KNP, and at least two cattle farms in the area were confirmed to be infected with BTB (Renwick et al. 2007). In addition, at that time several cattle on these farms died of Corridor disease (Theileriosis) which is a buffalo-associated disease, illustrating contact between these species. The infection of buffalo is therefore believed to have occurred at this time.

BTB has since been detected in buffalo herds throughout the KNP, and buffalo are recognised as the primary maintenance host of the disease in this ecosystem. Other wildlife species such as Greater Kudu (Fig. 10.3), Warthogs, Cheetahs, Leopards, Black and White Rhinoceros, Chacma Baboons and Lions have all been diagnosed with clinical BTB (Renwick et al. 2007; Miller et al. 2017) with speculation that kudu, lions and warthogs have the potential to be maintenance hosts of the disease as well. As in the case of rabies, the social nature of certain species facilitates establishment and transmission of BTB in a population due to close contact. Because BTB is a chronic disease, infected animals have the potential to remain in their herds for months to years and infect others for long periods before succumbing to the disease. Social support systems also enable sick animals to survive for longer and 


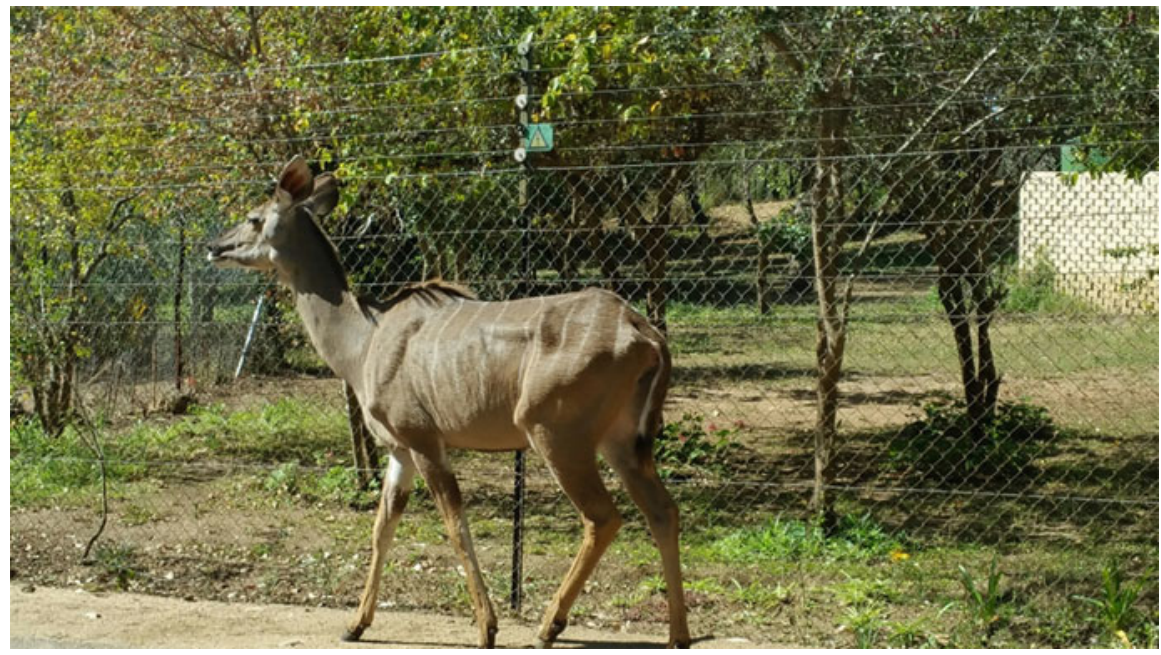

Fig. 10.3 Free ranging kudu in the staff village, Skukuza, Kruger National Park, with clear signs of bovine TB, namely poor body condition and enlarged lymph nodes in angle of jaw. Photograph courtesy of M. Miller

thus have more opportunities to infect others. For instance, sick lions may be unable to hunt for themselves, but are provided with food by their pride members, who may become infected through prolonged contact (Renwick et al. 2007).

Infection with BTB causes loss of body condition, decreased fertility and respiratory issues. However, because of the slow progressing nature of the infection, the effects in wildlife populations are difficult to observe and currently remain unknown. Studies in the 1990s in KNP buffalo found that younger individuals were overrepresented in BTB-infected herds, possibly due to an increased mortality rate in older buffalo, but that there was no difference in numbers of pregnant and lactating females in infected vs. uninfected herds (Rodwell et al. 2001b). However, a later study showed the opposite effect, with infected herds having decreased body condition and an apparently decreased calf survival rate (Caron et al. 2003). Studies of infected buffalo in the HiP showed a reduced population growth and adult survival rate (Jolles et al. 2005). As BTB does not exist in a vacuum, these effects are confounded by concurrent factors that may have an effect on populations, such as drought and other diseases (Michel et al. 2006).

BTB-infected animals suffering from clinical disease are more likely to be killed by predators, providing a means of transmission up the food chain. BTB was first detected in lions in the KNP in 1996, presumably infected by eating infected buffalo meat or inhaling infected body fluids while doing so (Keet et al. 1996). BTB appears to have a destabilising effect on lion prides, as the deaths of dominant animals render the pride vulnerable to attack or takeover from other neighbouring prides. Infected lion populations were observed to have distorted age and sex ratios, with higher mortality among older and adult lions, and a male to female ratio four times higher 
than normal (Keet et al. 2000). Although it is clear that BTB has caused lion mortality in KNP (Michel et al. 2006), which would suggest a projected decrease in population (Keet et al. 2009), others assert that at a population level this is unlikely (Ferreira and Funston 2010; Kosmala et al. 2016). However, since lions are already facing threats posed by habitat loss, poaching and feline immunodeficiency virus (Renwick et al. 2007), the cumulative effect these factors plus BTB on their population has the potential to be devastating. The global lion population has decreased by $43 \%$ over the last three generations. Lion populations in southern Africa are the most stable, and it is the only remaining area where lions are not persecuted to the extent of being classified as endangered by the IUCN (Bauer et al. 2016). The health of lions in southern Africa may therefore be important for preserving their species in the wild.

Control of BTB once it is established in wildlife populations is challenging, but a reduction in disease prevalence has been seen in HiP after the use of an intensive programme to test buffalo and cull those that test positive (Renwick et al. 2007; Cooper 2012). While this approach is of benefit to the population within HiP, it is still an infected population and there are therefore restrictions on translocations of animals out of the park. This disrupts programmes which aim to increase genetic diversity of wildlife species by moving animals between isolated conservation areas. There is currently no effective vaccine to combat tuberculosis either in animals or humans.

A voluntary testing programme exists for cattle herds in South Africa, so eradicating BTB in cattle is probably unlikely. African Buffalo in the country have to be tested before each translocation, to try and keep BTB out of other parks, but warthogs and Greater Kudu can travel long distance and spread over the country if they wish, therefore are problematic species if they are maintenance hosts.

Although infection of South African wildlife was originally caused by cattle, BTB-infected wildlife now pose a risk to domestic livestock. The existence of the disease in wildlife could, therefore, cause conservation efforts to be viewed negatively by livestock owners living close to conservation areas. Ecotourism could also be negatively affected by the influence of the disease on wildlife populations, or by perceptions of tourists when encountering diseased animals. Furthermore, conservation resources are extremely limited and can be allocated to disease control only when captured animals are earmarked for movement to a new area.

BTB is an example of an invasive disease whose effects in wildlife systems are, as yet, unclear. However, that changes in the population structure of some species within an ecosystem harbouring BTB will occur, seems likely. In the case of domestic stock, however, there are many consequences of disease, amongst which are economic costs to owners. 


\subsubsection{Rinderpest}

Perhaps the most dramatic example of an invasive animal disease was rinderpest. This virus, which expanded its reach to affect the globe, is now distinguished as the second infectious disease to be globally eradicated (the first being smallpox, see below) (World Organisation for Animal Health 2011; Roeder 2011; Roeder et al. 2013). It is a classic example of an introduced disease with devastating consequences. However, due to rapid transmission through a susceptible population with near $100 \%$ fatality, it did not become endemic in South Africa. It was known in Roman times as a pestilence of cattle and other ruminants (Barrett and Rossiter 1999). It is caused by a morbillivirus, and its precursor most likely gave rise also to the human disease, measles (Haas and Barrett 1996; Pearce-Duvet 2006). Introduced from Asia in the mid 1800s, rinderpest killed hundreds of millions of cattle in Europe (Roeder 2011), making it a dreaded disease. It causes erosions in the gastro-intestinal tract, resulting in severe diarrhoea and death from dehydration (Rossiter 1995).

Rinderpest was detected for the first time in South Africa in the Groot Marico district in 1896 (Vogel and Heyne 1996) (Fig. 10.4). This was not entirely unexpected, since its steady move southwards in Africa during the previous decade had been noted. It had most likely entered Africa with cattle imported from Russia or India in 1889 to feed Italian troops in Ethiopia and Eritrea. By 1896 it had reached the Zambezi, and in March of that year South Africa was notified that it had reached Bulawayo. Despite clearing a 3-mile strip of land, the disease crossed the border and continued its southward march until it crossed the Orange River. Various expensive
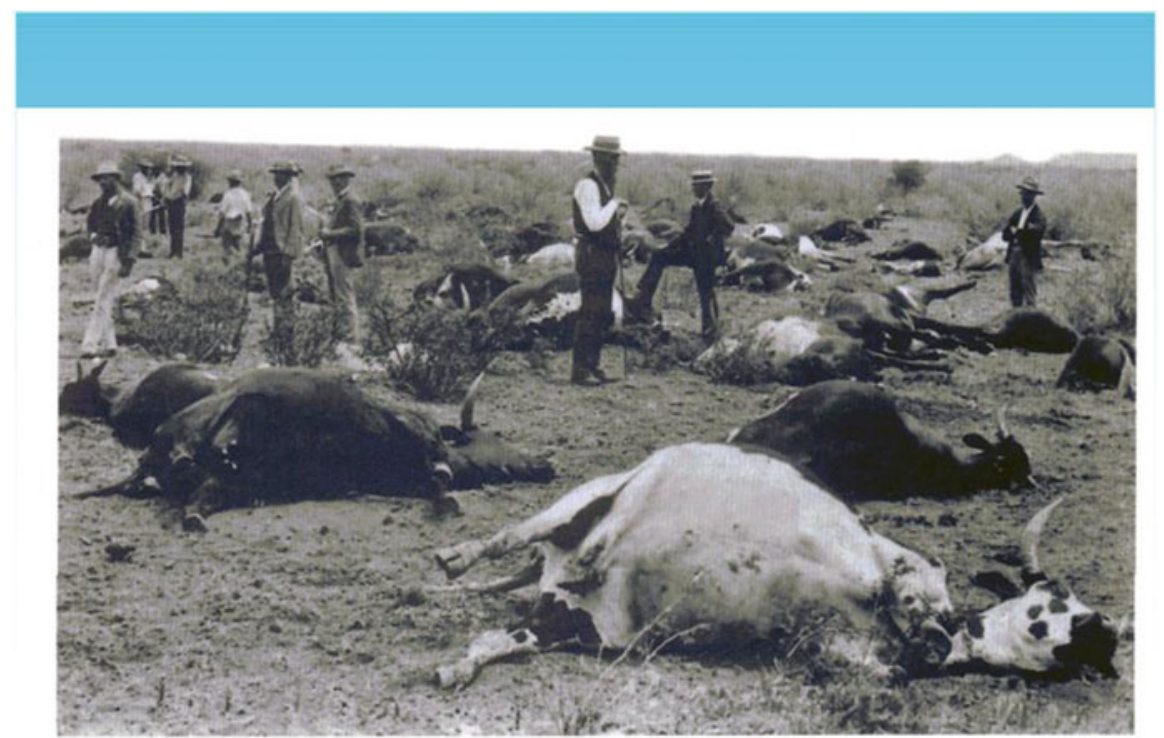

Fig. 10.4 Cattle deaths from rinderpest in 1896 in South Africa. Photograph courtesy of Wikipedia 
infrastructure was erected (including fences and double fences), and strict movement controls were imposed, but these failed to contain the spread. By the time it reached southern Zimbabwe, it had laid waste to cattle populations in those countries. The Ndebele people of southern Zimbabwe held the colonists responsible for the disease outbreak which deprived them of their cattle, and 244 Europeans were killed partly in retaliation. Transport of goods almost ceased, because no oxen were available to pull wagons and horse sickness limited equine use. The effect of rinderpest invasion was so rapid and dramatic that transport routes were littered with abandoned wagons filled with goods (Vogel and Heyne 1996). An estimate of 2.5 million cattle deaths alone in southern Africa has been made and in some districts only 3-7\% of the original cattle population remained. No accurate estimates of mortality in wild animals can be made, but clearly informal reports suggest that mortality must have been similar in wild mammals. Evidence for this is that the ecosystem was altered, with tall rank grass unsuitable for small stock and the disappearance of tsetse flies from former habitat owing to the lack of suitable wildlife species. To this day, tsetse flies are still absent from KNP. We do not know in what other ways contemporary ecosystems in the KNP were affected by rinderpest: some have suggested that the tree/grass community changed dramatically, and that tree diversity changed dramatically. For example, many large trees in KNP today are around 100 years old. In other words, they had opportunity to germinate and grow with no browsing pressure until they reached a large enough size to survive. There are suggestions that the same species are not represented in similar numbers of a younger age cohort (personal observation and discussion with local individuals). This is an area ripe for research and consideration.

Such ecosystem effects were seen in the Serengeti National Park (Holdo et al. 2009) when historical data were examined for evidence of the associations between fire, rainfall, atmospheric $\mathrm{CO}_{2}$, elephants and wildebeest on tree density. When wildebeest numbers rose after the eradication of rinderpest in the 1960s, grazing increased dramatically. Modelling of the available data suggested that the lower fuel load from more intense grazing before the rinderpest era resulted in fewer fires, which in turn resulted in more trees (Holdo et al. 2009). Likewise, it has been shown that herbivory and fire are competitive major drivers of vegetation dynamics in the Kruger Park savanna system, and that herbivory affects fire which in turn leads to changes in biodiversity (Smit and Archibald 2019). In effect, reduction in herbivory would have resulted in more grass, more fires and more intense fires with consequent changes in the ecosystem.

The effect of rinderpest on human populations was severe: farmers and communities not served by railway became isolated. Many rural people faced starvation and families became bankrupt. Famine broke out because crop production became almost impossible. There was mass migration to work on the mines in Johannesburg and Kimberley, leading to the development of the first slums in South Africa, and many political issues that persist today. Although the estimated direct financial loss of this epidemic was about ZAR 1.6 billion (adjusted to July 2018 value), the indirect costs would have exceeded that sum, particularly when we consider that South Africa has been irreversibly shaped by some of the consequences of this 
epidemic. The last rinderpest death in South Africa was in 1903 (Vogel and Heyne 1996). Fortunately, the disease is tractable to vaccination, and large-scale consistent vaccination and surveillance campaigns led to a reduction in disease occurrence and finally in 2011 rinderpest was officially declared eradicated globally. A key component of this campaign was perhaps counter-intuitively the decision to stop wide-scale vaccination once a few disease pockets were left in order to detect outbreaks of the disease more easily (de Swart et al. 2012). Cattle in such pockets were then either vaccinated or culled. The success of this campaign essentially relates to the removal of a supply of accessible and susceptible hosts which can act as transmission sources.

\subsection{Human Diseases}

Whilst humans are often the source or cause of invasive diseases, they can also be their victims. Both rabies and BTB are zoonotic diseases (i.e. infectious diseases that can be transmitted between animals and humans), which can cause severe illness and fatalities in people in the same manner that they do in other mammal species. South African history has also been shaped by outbreaks of human diseases that have made an indelible mark on society.

\subsubsection{Smallpox}

Smallpox was a global scourge and was most likely introduced to South Africa by early travellers and settlers from Europe. Devastation of indigenous people followed. As for rinderpest and measles, a very effective vaccine is available, and concerted efforts led to the global eradication of smallpox in 1980, the first infectious disease to be formally declared as eradicated (Breman and Arita 1980; Strassburg 1982).

Smallpox was an ailment unfamiliar to the indigenous people of the Cape when European settlers first arrived. Several Khoekhoe leaders in a statement to the governor of the Cape in 1678 stated that "no particularly severe sicknesses are known among them, and Death usually contents himself with old worn out people." Unfortunately, this meant that these indigenous people had no acquired immunity to diseases brought to their shores by immigrants. Reports of large outbreaks of disease among the Khoekhoe were recorded beginning in the second half of the seventeenth century, causing many deaths and causing the affected groups to move from place to place, attempting unsuccessfully to flee the disease (Moodie and Smith 1960). The largest outbreak of smallpox came in 1713, and it proved to be disastrous for the Khoekhoe people who had already suffered disease outbreaks, as well as having had their community and social structures disrupted by colonists (Phillips 2012). A large percentage of the population of Khoekhoe died within 6 months of the beginning of the outbreak, with some groups reporting mortalities of up to 90\% (Ross 1977). Abandoned settlements and livestock occurred wherever the outbreak had struck. Subsequent outbreaks in the eighteenth century penetrated further into the interior, 
causing high mortalities as far as the Transkei and Transgariep. Land was vacated, allowing settlers to occupy more of the country, while political and social structures disintegrated in the face of deaths of community leaders, large proportions of the population and almost entire generations of children. The scattered survivors were recruited as farm labourers. The use of smallpox vaccine at the beginning of the nineteenth century put a stop to outbreaks of the disease in South Africa, but it was too late for the indigenous way of life of the Khoekhoe, whose society had collapsed and many had now transitioned into being permanent farm labourers (Phillips 2012).

\subsubsection{Measles}

The measles and rinderpest viruses share a common ancestor, but whereas rinderpest evolved to specialise in ruminants, measles evolved to specialise in humans. Thus we consider that measles most likely evolved where humans and cattle were in close contact, and the first good records of measles outbreaks date from the eleventh or twelfth centuries. It is likely that at this time, the virus could switch hosts (Furuse et al. 2010). During the Middle Ages, measles became established as an endemic disease throughout the Middle East, North Africa and the Old World.

Spanish explorers took measles and smallpox to the New World, where they caused devastating epidemics in the early sixteenth century. Smallpox was evident in Mexico in 1515 and among the Incas by 1524. Measles probably appeared later, in 1529 (Retief and Cilliers 2010). Indigenous people in South Africa were similarly dramatically affected by measles. It is not possible to estimate what proportion of the population died from measles as opposed to other causes, but whole clans would disappear. The concentration camps established during the South African War (1898-1902), where large numbers of people were clustered together under poor living conditions, also gave impetus to measles-driven mortality and spread, particularly since most individuals were malnourished and stressed and exposed to many bacterial pathogens which may have rendered them hyper-susceptible (Shanks et al. 2014). Similar to rinderpest, the measles virus has spread globally and is tractable to vaccination. Unlike rinderpest, it is not yet eradicated, and the World Health Organization estimates that currently 400 children die per day from measles, and rather unexpectedly there is currently a growing epidemic, even in Europe (World Health Organization 2016). The development and worldwide deployment of an effective vaccine quickly led to a decline in measles cases (Greenwood 2014). Despite encouragement and provision of free wide-scale vaccination of newborns using a highly effective Measles, Mumps, and Rubella vaccine, not every South African infant, like those in many countries, is vaccinated (Ntshoe et al. 2013). There are various reasons for this, including poor access to health care for some individuals, and refusal to vaccinate in the case of others (Kagoné et al. 2017). This means that South Africa, like many other countries, has a population of susceptible individuals to continue hosting the disease, so we have a small number of active cases every year, with occasional outbreaks. Under these conditions, local and global eradication will be impossible. Essentially, the key difference between 
the eradication of rinderpest and measles is that humans can move freely, and cannot be forced to vaccinate or be culled.

\subsubsection{Human Immunodeficiency Virus}

The successes with the viruses discussed above, utilising large-scale campaigns to control and vaccinate, could suggest that similar success with human immunodeficiency virus (HIV) would be possible. This may yet be the case, but as of 2019 we have no successful HIV vaccine or cure, which gives rise to the problem we have today with this infectious agent. HIV is an example of an invasive disease that has become endemic, thanks to the long incubation period and social factors aiding its transmission.

This virus, finding itself at home in humans, has invaded the globe and in particular, South Africa, spectacularly. The virus is thought to have been a zoonotic pathogen that jumped to humans when humans had close contact with simians in West or Central Africa, possibly through consumption of bushmeat (Peeters et al. 2002). The dates of this or these events are disputed, but may be as early (or late, depending on one's perspective) as the early 1900s or even earlier. It first gained serious attention as an unusual health problem of unknown etiology in the early 1980s amongst the gay and drug-using communities in the USA (Luce 2013). It was first detected in South Africa in 1982 (Gilbert and Walker 2002). The causative virus was first isolated in 1983 (Barré-Sinoussi et al. 1983; Weiss 2003). The consequences of failure to contain this virus are very evident. UNAIDS estimates that South Africa has approximately 270,000 new HIV infections and 110,000 deaths every year (UNAIDS 2016).

The march of HIV through the South African human population, and the politics surrounding it, have received unprecedented media attention. Part of the reason for this is that HIV infection is currently irreversible and incurable (Humphry 1993). We now have drug cocktails that can halt the progression of the disease, but not cure it. The cost to the country is extraordinarily high. In 2016, UNAIDS estimated that there are 7.1 million people living with HIV in South Africa. Approximately 56\% of the infected persons receive antiretroviral treatment at a direct cost of over ZAR 66.4 billion per annum. Given our total National Department of Health budget of ZAR 205.4 billion, it can be seen that just this one single infectious agent has been an incredibly successful invader and now costs us a disproportionate amount of our health budget, which in turn is $13.9 \%$ of total government spend (South African National Department of Health 2018).

A further problem with HIV is the enhanced susceptibility to tuberculosis (TB) of HIV-positive individuals (Corbett et al. 2003). The ingress of HIV into South African society and rapid rise of prevalence, led to a parallel rise in human TB (caused by Mycobacterium tuberculosis) incidence and prevalence in South Africa, placing a double burden on the health care system. TB is also more difficult to diagnose in HIV-positive individuals (Aaron et al. 2004), further complicating the problem. 


\subsection{Infectious Agents That Have Moved Out of Africa}

Although this chapter discusses species introduced into southern Africa, pathogens are also introduced from southern Africa to other regions (see also Pyšek et al. 2020, Chap. 26; Measey et al. 2020, Chap. 27, for a discussion of South African species that have become invasive elsewhere). Two examples are discussed below.

\subsubsection{West Nile Virus}

West Nile Virus infection is caused by a mosquito-borne Flavivirus, which originated in Africa. A mosquito-bird cycle is the maintenance mechanism, and birds are considered to be amplifying hosts for the virus. This disease subsequently spread to the Middle East and then into Europe where it continues to cause sporadic outbreaks. However, the most dramatic course of events occurred when this virus was introduced into the United States of America in 1999. It is thought to have arrived with an infected mosquito by aircraft or ship, and was first seen in New York, when many birds began dying quite dramatically, some dropping out of the sky. This was followed within a few years by an unprecedented and well-documented spread right across continental North America, killing millions of birds and also affecting thousands of horses and many humans. Although $80 \%$ of infections in humans are sub-clinical, symptomatic infections range from a self-limiting fever to severe neurological disease with long-term sequelae and death (Suthar et al. 2013). The 2002 and 2003, West Nile Virus epidemics were the largest recognised arbovirus meningo-encephalitis epidemics in the western hemisphere, with more than 500 human deaths (Sejvar 2003). During these 2 years, a total of 13,278 human cases were reported in the USA, with a mortality rate of between 3 and $7 \%$ (Bengis et al. 2004). Many infected horses also died of neurological disease. Clinical disease and deaths were also recorded in 155 resident avian species.

This disease has now become endemic in North America, with focal outbreaks in birds, humans and horses occurring annually. West Nile Virus infection in the USA is a classic example of an alien vector-borne infection being introduced into a naïve ecosystem.

\subsubsection{African Swine Fever}

In the natural African environment, the African Swine Fever (ASF) virus circulates between soft ticks (tampans) and wild African suids such as warthogs and bush pigs, which become sub-clinically infected. However, in domestic swine, ASF infection becomes directly contagious and causes a severe, usually fatal, haemorrhagic disease. In the African context, ASF presents a severe limitation to commercial pig farming in areas where tampans and native wild porcines co-occur. African Swine 
Fever is caused by a monotypic Asfar virus, and until recently its distribution has been limited to sub-Saharan Africa, with occasional excursions into Spain and Sardinia. In 2007, ASF was introduced to the eastern European country of Georgia, in swill originating from a ship that had arrived from Mozambique (Rowlands et al. 2008). From Georgia, the disease spread northwards to Belarus, Ukraine, and western Russia, affecting both wild boars and domestic pigs. In 2014, the disease spread into Lithuania, and from there onto Latvia, Estonia and Poland (Śmietanka et al. 2016). The disease appears to be spread by wild boars, but the movement of carcasses and domestic pig products also appears to play an important role. The ASF virus is an extremely robust virus that can survive prolonged periods outside a host, and survive indefinitely in frozen pig products. It only affects pigs, and may result in $>90 \%$ mortality and there is currently no treatment or effective vaccine (Penrith et al. 2004). The only control options available are to control the movement of pigs and pig products, and slaughter infected herds, followed by burying or incinerating infected carcasses. The disease has now spread to Romania, the Czech Republic and Luxembourg, bringing it ever closer to the major pig-producing countries of Germany, Holland and Denmark (OIE 2018). This is of grave concern to the EU and the pig producers in those countries. What is even concerning is that the disease has now entered China from the north, and outbreaks have been reported in 21 locations in China. China is the biggest producer of pigs in the world, and pork is a staple protein across the whole of Southeast Asia. We are thus now faced with an alien viral infection which has spread through several naïve ecosystems and is having profound effects on wildlife (wild boar) and the domestic pig industry. There is every reason to believe this pandemic could have catastrophic outcomes, similar to the rinderpest outbreaks of the eighteenth, nineteenth and early twentieth centuries.

\subsection{The Future}

There is little doubt that as humans continue to expand their range into wild areas, new diseases will emerge and jump the species barrier to affect novel hosts. Examples of this are the haemorrhagic fevers such as Ebola, where frequent outbreaks have been recorded in Africa. In many cases, these risks will come from disrupted territories and more contact with animal species such as, but not limited to, bats (Marsh and Wang 2012) and rodents. Zoonotic disease is particularly likely from such activities and it is estimated that most infectious diseases that have emerged in the last 6 decades originated in wildlife (FAO 2013). The ubiquitous and diverse nature of influenza viruses suggests almost certain outbreaks of such pandemics in future, whether swine, avian or of the human variety.

Many diseases will arise from direct contact, but some will be driven by vectors such as mosquitos (Farajollahi et al. 2011) or ticks. Climate change is likely to allow expansion of vector areas, allowing potential for spread of diseases that previously could not be spread. There is a discrepancy in the way we look at diseases versus climate change. While climate change is studied at a global level, diseases are usually considered at a local or ecosystem level. Such thinking goes hand-in-hand 
with fragmentation of landscape, a risk factor for disease outbreaks, although in the context of disease, we would venture to say we have little understanding of the effects of landscape heterogeneity and general principles of invasion ecology (FAO 2013; White et al. 2018). This is unfortunate, since climate change and landscape heterogeneity can have a vast impact on the epidemiology of disease. Increased temperatures may cause an increase, or even possibly a decrease in some cases, in the number of diseases and an expansion in range of vectors and pathogens, while indirectly, land use and biodiversity are changed by the changing climatic conditions. Recently there has been an expansion in cases of diseases such as Zika, dengue, and yellow fever, which is a movement of these agents from wild to more urban environments (Ali et al. 2017; Hamrick et al. 2017). Some disease agents that are vector-borne develop faster within the mosquito at higher temperatures. In the host, increases in temperature cause a higher degree of physiological stress, decreasing immunity and therefore increasing the risk of disease. Additionally, a drying climate causes more farmers to switch to irrigating their crops, creating new habitats for vectors in previously unsuitable areas. Health professionals should, therefore, be aware of the effects of climate change in their areas and the previously undetected diseases that may emerge as a result. Climate change may facilitate range expansion within a country or expansion into a new country. This can be driven by the increased movement of people and their animals because of political and climate change, which is a threat for introduction of new diseases (Vorou et al. 2007). The watch-word here is geopolitical instability.

An example of a viral disease that poses a likely threat to South Africa is peste des petits ruminants (PPR) (Baazizi et al. 2017), which has been expanding its geographic range since it was identified in West Africa in the 1940s (Gargadennec and Lalanne 1942) (Fig. 10.5). It is currently the focus of a global eradication strategy. PPR resembles rinderpest, but infects sheep and goats instead of cattle, causing damage to the respiratory and gastro-intestinal mucosa and resulting in up to $90 \%$ mortality from diarrhoea and dehydration or secondary bacterial pneumonia (FAO 2015). The effect of PPR on wildlife, particularly smaller ruminants, is currently unclear. PPR has resulted in high mortalities in Asian wildlife, including Ovis orientalis (Wild Sheep), Capra aegagrus (Goat) and Gazella subgutturosa (Blacktailed Gazelle) in Iran (Marashi et al. 2017) and several wildlife species kept in captivity (Munir 2014). Should PPR successfully invade South Africa, the possibility exists that it could cause a wide-scale outbreak affecting either or both domestic livestock and wildlife. It is also possible that the disease could establish itself in a wildlife reservoir, from where it could repeatedly spill over to domestic livestock, although this situation has not been observed in infected countries. The threat of PPR is exacerbated by climate change. As regions become drier, farming practices move from the keeping of cattle to sheep and goats, which are more adaptable in drought situations (Rust and Rust 2013). PPR, therefore, has a higher population of susceptible hosts available, and can have a more substantial impact on animal populations and food security in regions which are already experiencing climate change or ecosystem damage. Vaccines are being developed and will hopefully be effective against this problem. 


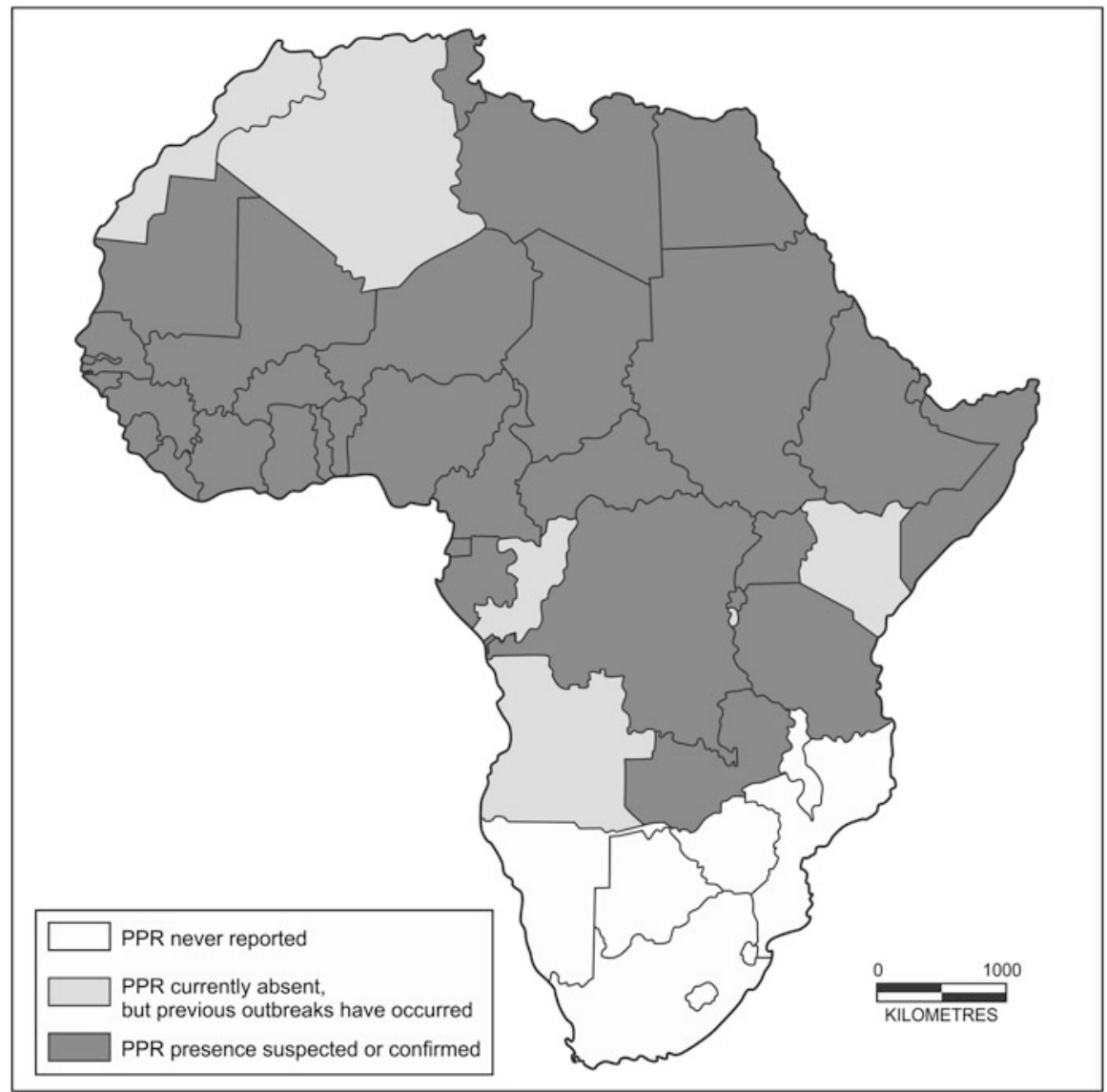

Fig. 10.5 The status of peste des petits ruminants (PPR) in livestock in African countries at the end of 2017. Data obtained from the World Organisation for Animal Health (2018)

To address the problems of old and new or emerging disease, research and development is needed to produce good diagnostics and vaccines for multiple species. Such diagnostics must be of high sensitivity and specificity. It is essential that policies are developed to interpret diagnostic results from surveillance as a function of sensitivity and specificity of diagnostic tests, since interpretation can be different in high or low-incidence areas. Restricting the movement of animals to control disease has been used for over a century or more and can be highly effective in some cases, such as limiting the range expansion of foot and mouth disease in bovids, and restricting expansion of African horse sickness in the Western Cape. Movement control is unfortunately not always possible: for example, it is likely to be impossible to deal easily with disease carried by bats or migratory birds, but in many cases, control in the case of short distance dispersal is possible.

Where possible, vaccination can be highly effective, as it was in the successful eradication of smallpox and rinderpest, for example. However, vaccination can 
sometimes affect diagnostic tests, making disease control difficult. Prevention at each step i.e. entry, transmission and establishment should be done. Early detection and surveillance with a contingency plan to control or eliminate the disease as quickly as possible is necessary.

Eradication is possible in some cases (examples given earlier) but it takes a long time, is difficult and costly, and therefore control is the aim of most disease-related interventions. Cost should not, however, be the main consideration for attempting control (Thompson 2014). We should try to ensure that the benefits of control will outweigh costs, bearing in mind that if eradication is impossible, control may be required indefinitely. To eradicate any disease, the cost rises as the incidence drops.

One should not lose sight of the fact that infectious disease is likely here to stay. Disease is also a "population control" and evolutionary driver. It is not only the disease agents that evolve over time, generating new strains, but the hosts also evolve to try to cope with infection. Thus, we see huge diversity in mammalian immune systems, for example. This means that a new disease in a naïve population may have an initially devastating effect, but over time this can settle to an equilibrium. An example of this is foot and mouth disease, which African buffalo harbour with few serious consequences. However, domestic cattle are affected negatively by foot and mouth disease.

Finally, although diseases are unlikely to cause extinctions in populations of relatively common wild animal species, they can severely affect endangered species with low populations, and that are already facing numerous other threats, and in such cases diseases could be the final factor that results in extinction.

Acknowledgements The authors were supported by the South African Medical Research Council and the National Research Foundation of South Africa. Dr. Roy Bengis and Dr. Harry Biggs are thanked for helpful suggestions.

\section{References}

Aaron L, Saadoun D, Calatroni I et al (2004) Tuberculosis in HIV-infected patients: a comprehensive review. Clin Microbiol Infect 10:388-398. https://doi.org/10.1111/j.1469-0691.2004. 00758.x

Acevedo-Whitehouse K, Duffus ALJ (2009) Effects of environmental change on wildlife health. Philos Trans R Soc B Biol Sci 364:3429-3438. https://doi.org/10.1098/rstb.2009.0128

Aguirre AA (2009) Wild canids as sentinels of ecological health: a conservation medicine perspective. Parasit Vectors 2:S7. https://doi.org/10.1186/1756-3305-2-S1-S7

Ali S, Gugliemini O, Harber S et al (2017) Environmental and social change drive the explosive emergence of Zika Virus in the Americas. PLoS Negl Trop Dis 11:e0005135. https://doi.org/10. 1371/journal.pntd.0005135

Baazizi R, Mahapatra M, Clarke BD et al (2017) Peste des petits ruminants (PPR): a neglected tropical disease in Maghreb region of North Africa and its threat to Europe. PLoS One 12: e0175461. https://doi.org/10.1371/journal.pone.0175461

Barré-Sinoussi F, Chermann JC, Rey F et al (1983) Isolation of a T-lymphotropic retrovirus from a patient at risk for acquired immune deficiency syndrome (AIDS). Science 220:868-871. https:// doi.org/10.1126/science.6189183 
Barrett T, Rossiter PB (1999) Rinderpest: the disease and its impact on humans and animals. Adv Virus Res 53:89-110. https://doi.org/10.1016/S0065-3527(08)60344-9

Bauer H, Packer C, Funston PF, Henschel P, Nowell K (2016) The IUCN red list of threatened species 2016: e.T15951A97162455. https://doi.org/10.2305/IUCN.UK.2016-3.RLTS. T15951A107265605.en

Bengis RG, Kriek NP, Keet DF et al (1996) An outbreak of bovine tuberculosis in a free-living African buffalo (Syncerus caffer--sparrman) population in the Kruger National Park: a preliminary report. Onderstepoort J Vet Res 63:15-18

Bengis RG, Leighton FA, Fischer JR et al (2004) The role of wildlife in emerging and re-emerging zoonoses. Rev Sci Tech 23:497-511

Bergmann GT (2017) Microbial community composition along the digestive tract in forage- and grain-fed bison. BMC Vet Res 13(1):253. https://doi.org/10.1186/s12917-017-1161-x

Berry HH (1993) Surveillance and control of anthrax and rabies in wild herbivores and carnivores in Namibia. Rev Sci Tech 12:137-146. https://doi.org/10.20506/rst.12.1.675

Bocquet-Appel J-P (2011) When the world's population took off: the springboard of the Neolithic demographic transition. Science 333:560-561. https://doi.org/10.1126/science.1208880

Breman JG, Arita I (1980) The confirmation and maintenance of smallpox eradication. N Engl J Med 303:1263-1273. https://doi.org/10.1056/NEJM198011273032204

Caron A, Cross PC, du Toit JT (2003) Ecological implications of bovine tuberculosis in African Buffalo herds. Ecol Appl 13:8. https://doi.org/10.1890/02-5266

Castro FD, Bolker BM (2005) Parasite establishment and host extinction in model communities. Oikos 111:501-513. https://doi.org/10.1111/j.1600-0706.2005.14101.x

Centers for Disease Control and Prevention (2012) Principles of epidemiology in public health practice. In: An introduction to applied epidemiology and biostatistics, 3rd edn. Public Health Foundation, Washington, DC

Coetzee P, Nel LH (2007) Emerging epidemic dog rabies in coastal South Africa: a molecular epidemiological analysis. Virus Res 126:186-195. https://doi.org/10.1016/j.virusres.2007.02. 020

Cooper D (2012) Bovine tuberculosis control in Hluhluwe iMfolozi Park 1999-2012. In: Paper presented at the International Wildlife TB Conference, Kruger National Park, Skukuza

Corbett EL, Watt CJ, Walker N et al (2003) The growing burden of tuberculosis: global trends and interactions with the HIV epidemic. Arch Intern Med 163:1009-1021. https://doi.org/10.1001/ archinte.163.9.1009

Courtin F, Carpenter TE, Paskin RD, Chomel BB (2000) Temporal patterns of domestic and wildlife rabies in central Namibia stock-ranching area, 1986-1996. Prev Vet Med 43:13-28. https://doi.org/10.1016/S0167-5877(99)00083-5

DAFF (2013) Interim bovine tuberculosis scheme manual. http://www.nda.agric.za/vetweb/Pam phlets\&Information/Policy/TB\%20Manual\%20\%206Dec2013\%20interim\%20signed.pdf

de Garine-Wichatitsky M, Caron A, Gomo C et al (2010) Bovine tuberculosis in buffaloes, Southern Africa. Emerg Infect Dis 16:884-885. https://doi.org/10.3201/eid1605.090710

de Swart RL, Duprex WP, Osterhaus ADME (2012) Rinderpest eradication: lessons for measles eradication? Curr Opin Virol 2:330-334. https://doi.org/10.1016/j.coviro.2012.02.010

De Vos V, Bengis RG, Kriek NP et al (2001) The epidemiology of tuberculosis in free-ranging African buffalo (Syncerus caffer) in the Kruger National Park, South Africa. Onderstepoort J Vet Res 68:119-130

Deem SL, Karesh WB, Weisman W (2001) Putting theory into practice: wildlife health in conservation. Conserv Biol 15:1224-1233. https://doi.org/10.1046/j.1523-1739.2001.00336.x

Department of Agriculture, Forestry and Fisheries (DAFF) (2018) Disease database. https://www. nda.agric.za/vetweb/epidemiology/Disease\%20Database/OIEData/OIE_query_Criteria.asp. Accessed 7 Feb 2019

FAO (2013) The state of food and agriculture 2013. Food and Agricultural Organisation, Rome

FAO (2015) Global strategy for the control and eradication of PPR. In: ReliefWeb. https:// reliefweb.int/report/world/global-strategy-control-and-eradication-ppr. Accessed 26 Sep 2018 
Farajollahi A, Fonseca DM, Kramer LD, Marm Kilpatrick A (2011) "Bird biting" mosquitoes and human disease: a review of the role of Culex pipiens complex mosquitoes in epidemiology. Infect Genet Evol 11:1577-1585. https://doi.org/10.1016/j.meegid.2011.08.013

Ferreira SM, Funston PJ (2010) Estimating lion population variables: prey and disease effects in Kruger National Park, South Africa. Wildl Res 37:194-120. https://doi.org/10.1071/WR09030

Foggin CM (1988) Rabies and rabies-related viruses in Zimbabwe: historical, virological and ecological aspects. Dissertation, University of Zimbabwe

Franka R, Rupprecht CE (2011) Treatment of rabies in the 21st century: curing the incurable? Future Microbiol 6:1135-1140. https://doi.org/10.2217/fmb.11.92

Furuse Y, Suzuki A, Oshitani H (2010) Origin of measles virus: divergence from rinderpest virus between the 11th and 12th centuries. Virol J 7:52. https://doi.org/10.1186/1743-422X-7-52

Gargadennec L, Lalanne A (1942) La peste-des-petits-ruminants. Bull Serv Zoo AOF 5:16-21

Gerber LR, McCallum H, Lafferty KD et al (2005) Exposing extinction risk analysis to pathogens: is disease just another form of density dependence? Ecol Appl 15:1402-1414. https://doi.org/ $10.1890 / 04-0880$

Gilbert L, Walker L (2002) HIV/AIDS in South Africa: an overview. Cad Saúde Pública 18:651-660. https://doi.org/10.1590/S0102-311X2002000300009

Greenwood B (2014) The contribution of vaccination to global health: past, present and future. Philos Trans R Soc B 369:20130433. https://doi.org/10.1098/rstb.2013.0433

Gunderson L, Holling CS, Light S (eds) (1995) Barriers and bridges to the renewal of ecosystems and institutions. Columbia University Press, New York

Haas L, Barrett T (1996) Rinderpest and other animal morbillivirus infections: comparative aspects and recent developments. J Vet Med Ser B 43:411-420. https://doi.org/10.1111/j.1439-0450. 1996.tb00333.x

Hamrick PN, Aldighieri S, Machado G et al (2017) Geographic patterns and environmental factors associated with human yellow fever presence in the Americas. PLoS Negl Trop Dis 11: e0005897. https://doi.org/10.1371/journal.pntd.0005897

Harari YN (2015) Sapiens: a brief history of humankind. HarperCollins, New York

Hatcher MJ, Dick JT, Dunn AM (2012) Diverse effects of parasites in ecosystems: linking interdependent processes. Front Ecol Environ 10:186-194. https://doi.org/10.1890/110016

Herzenberg L (1928) Two cases of hydrophobia. S Afr Med J 2:659-661

Hofmeyr M, Bingham J, Lane EP et al (2000) Rabies in African wild dogs (Lycaon pictus) in the Madikwe Game Reserve, South Africa. Vet Rec 146:50-52. https://doi.org/10.1136/vr.146.2.50

Hofmeyr M, Hofmeyr D, Nel L, Bingham J (2004) A second outbreak of rabies in African wild dogs (Lycaon pictus) in Madikwe Game Reserve, South Africa, demonstrating the efficacy of vaccination against natural rabies challenge. Anim Conserv 7:193-198. https://doi.org/10.1017/ S1367943004001234

Holdo RM, Sinclair ARE, Dobson AP et al (2009) A disease-mediated trophic cascade in the Serengeti and its implications for ecosystem C. PLoS Biol 7:e1000210. https://doi.org/10.1371/ journal.pbio. 1000210

Huchzermeyer HFK, Brückner GK, van Heerden A et al (1994) Tuberculosis. In: Coetzer JAW, Thomson GR, Tustin RC (eds) Infectious diseases of livestock with special reference to Southern Africa. Oxford University Press, Cape Town, pp 1425-1445

Humphry D (1993) Lawful exit: the limits of freedom for help in dying. The Norris Lane Press, Junction City

Hutcheon D (1880) Tering, consumption, tables mesenterica. Annual report, Colonial Veterinary Surgeon, Cape of Good Hope

Hutcheon D (1984) Reports for the colonial veterinary surgeon and assistant veterinary surgeons for the year 1893. Department of Agriculture, Cape of Good Hope

Jolles AE, Cooper DV, Levin SA (2005) Hidden effects of chronic tuberculosis in African Buffalo. Ecology 86:2358-2364. https://doi.org/10.1890/05-0038

Jones JH (2007) Notes on R0. Department of Anthropological Sciences, Stanford University

Kagoné M, Yé M, Nébié E et al (2017) Vaccination coverage and factors associated with adherence to the vaccination schedule in young children of a rural area in Burkina Faso. Glob Health Action 10(1):1399749. https://doi.org/10.1080/16549716.2017.1399749 
Keet DF, Kriek NP, Penrith ML et al (1996) Tuberculosis in buffaloes (Syncerus caffer) in the Kruger National Park: spread of the disease to other species. Onderstepoort J Vet Res 63:239-244

Keet DF, Michel A, Meltzer DGA (2000) Tuberculosis in free-ranging lions (Panthera leo) in the Kruger National Park. In: Proceedings of the South African Veterinary Association biennial congress, pp 232-241

Keet DF, Davies-Mostert H, Bengis R et al (2009) African lion (Panthera leo) bovine tuberculosis. In: Disease risk assessment workshop report, Skukuza

Kosmala M, Miller P, Ferreira S et al (2016) Estimating wildlife disease dynamics in complex systems using an approximate Bayesian computation framework. Ecol Appl 26:295-308. https://doi.org/10.1890/14-1808

Koyuncu OO, Hogue IB, Enquist LW (2013) Virus infections in the nervous system. Cell Host Microbe 13:379-393. https://doi.org/10.1016/j.chom.2013.03.010

Luce JM (2013) A strange new disease in San Francisco. A brief history of the city and its response to the HIV/AIDS epidemic. Ann Am Thorac Soc 10:143-147. https://doi.org/10.1513/ AnnalsATS.201208-039PS

MacHugh DE, Larson G, Orlando L (2017) Taming the past: ancient DNA and the study of animal domestication. Annu Rev Anim Biosci 5:329-351. https://doi.org/10.1146/annurev-animal022516-022747

Mansfield K, McElhinney L, Hübschle O et al (2006) A molecular epidemiological study of rabies epizootics in kudu (Tragelaphus strepsiceros) in Namibia. BMC Vet Res 2:2. https://doi.org/10. 1186/1746-6148-2-2

Mansvelt PR (1956) Rabies in the Northern Transvaal (1950 outbreak). J S Afr Vet Assoc 27:167-178

Marashi M, Masoudi S, Moghadam MK et al (2017) Peste des Petits Ruminants Virus in vulnerable wild small ruminants, Iran, 2014-2016. Emerg Infect Dis 23:704-706. https://doi.org/10.3201/ eid2304.161218

Marsh GA, Wang L-F (2012) Hendra and Nipah viruses: why are they so deadly? Curr Opin Virol 2:242-247. https://doi.org/10.1016/j.coviro.2012.03.006

Measey J, Robinson TB, Kruger N et al (2020) South Africa as a donor of alien animals. In: van Wilgen BW, Measey J, Richardson DM et al (eds) Biological invasions in South Africa. Springer, Berlin, pp 783-826. https://doi.org/10.1007/978-3-030-32394-3_27

Michel AL, Bengis RG, Keet DF et al (2006) Wildlife tuberculosis in South African conservation areas: implications and challenges. Vet Microbiol 112:91-100. https://doi.org/10.1016/j.vetmic. 2005.11.035

Miller MA, Buss PE, van Helden PD, Parsons SDC (2017) Mycobacterium bovis in a free-ranging black rhinoceros, Kruger National Park, South Africa, 2016. Emerg Infect Dis 23:557-558. https://doi.org/10.3201/eid2303.161622

Moodie D, Smith AH (1960) The record; or, a series of official papers relative to the condition and treatment of the native tribes of South Africa. A.A. Balkema, Cape Town

Morris RS, Pfeiffer DU, Jackson R (1994) The epidemiology of Mycobacterium bovis infections. Vet Microbiol 40:153-177. https://doi.org/10.1016/0378-1135(94)90053-1

Munir M (2014) Role of wild small ruminants in the epidemiology of peste des petits ruminants. Transbound Emerg Dis 61:411-424. https://doi.org/10.1111/tbed.12052

Murphy FA (1977) Rabies pathogenesis. Arch Virol 54:279-297. https://doi.org/10.1007/ BF01314774

Nel JA (1993) The bat-eared fox: a prime candidate for rabies vector? Onderstepoort J Vet Res 60:395-397

Ntshoe GM, McAnerney JM, Archer BN et al (2013) Measles outbreak in South Africa: epidemiology of laboratory-confirmed measles cases and assessment of intervention, 2009-2011. PLoS One 8:e55682. https://doi.org/10.1371/journal.pone.0055682

OIE (2018) Meat tracking key to fight African swine fever. https://ewn.co.za/2018/09/11/meattracking-key-to-fight-african-swine-fever-oie. Accessed 11 Feb 2019

Pearce-Duvet JMC (2006) The origin of human pathogens: evaluating the role of agriculture and domestic animals in the evolution of human disease. Biol Rev 81:369-382. https://doi.org/10. $1017 / \mathrm{S} 1464793106007020$ 
Peeters M, Courgnaud V, Abela B et al (2002) Risk to human health from a plethora of simian immunodeficiency viruses in primate bushmeat. Emerg Infect Dis 8:451-457. https://doi.org/ 10.3201/eid0805.010522

Penrith M-L, Thomson GR, Bastos ADS (2004) African swine fever. In: Coetzer JAW, Tustin RC (eds) Infectious diseases of livestock, 2nd edn. Oxford University Press, Cape Town, pp $1088-1119$

Phillips H (2012) Plague, pox and pandemics: a Jacana pocket history of epidemics in South Africa. Jacana Media, Johannesburg

Pyšek P, Pergl J, van Kleunen M et al (2020) South Africa as a donor of naturalized and invasive plants to other parts of the world. In: van Wilgen BW, Measey J, Richardson DM et al (eds) Biological invasions in South Africa. Springer, Berlin, pp 755-782. https://doi.org/10.1007/ 978-3-030-32394-3_26

Randall DA, Williams SD, Kuzmin IV et al (2004) Rabies in endangered Ethiopian wolves. Emerg Infect Dis 10:2214-2217. https://doi.org/10.3201/eid1012.040080

Renwick AR, White PCL, Bengis RG (2007) Bovine tuberculosis in southern African wildlife: a multi-species host-pathogen system. Epidemiol Infect 135:529-540. https://doi.org/10.1017/ S0950268806007205

Retief F, Cilliers L (2010) Measles in antiquity and the middle ages. S Afr Med J 100:216-217. https://doi.org/10.7196/SAMJ.3504

Rodwell TC, Kriek NP, Bengis RG et al (2001a) Prevalence of bovine tuberculosis in African buffalo at Kruger National Park. J Wildl Dis 37:258-264. https://doi.org/10.7589/0090-355837.2.258

Rodwell TC, Whyte IJ, Boyce WM (2001b) Evaluation of population effects of bovine tuberculosis in free-ranging African Buffalo (Syncerus caffer). J Mammal 82:231-238

Roeder PL (2011) Rinderpest: the end of cattle plague. Prev Vet Med 102:98-106. https://doi.org/ 10.1016/j.prevetmed.2011.04.004

Roeder P, Mariner J, Kock R (2013) Rinderpest: the veterinary perspective on eradication. Philos Trans R Soc B Biol Sci 368:20120139. https://doi.org/10.1098/rstb.2012.0139

Ross R (1977) Smallpox at the Cape of Good Hope in the eighteenth century. Afr Hist Demogr:416-428

Rossiter PB (1995) Rinderpest. In: Coetzer JAW, Thomson GR, Tustin RC (eds) Infectious diseases of livestock with special reference to Southern Africa. Oxford University Press, Cape Town, pp 735-757

Rowlands RJ, Michaud V, Heath L et al (2008) African swine fever virus isolate, Georgia, 2007. Emerg Infect Dis 14:1870-1874. https://doi.org/10.3201/eid1412.080591

Rust JM, Rust T (2013) Climate change and livestock production: a review with emphasis on Africa. S Afr J Anim Sci 43:256-267. https://doi.org/10.4314/sajas.v43i3.3

Sabeta CT, Mansfield KL, McElhinney LM et al (2007) Molecular epidemiology of rabies in bat-eared foxes (Otocyon megalotis) in South Africa. Virus Res 129:1-10. https://doi.org/10. 1016/j.virusres.2007.04.024

Scott TP, Fischer M, Khaiseb S et al (2013) Complete genome and molecular epidemiological data infer the maintenance of rabies among Kudu (Tragelaphus strepsiceros) in Namibia. PLoS One 8:e58739. https://doi.org/10.1371/journal.pone.0058739

Sejvar JJ (2003) West Nile virus: an historical overview. Ochsner J 5:6-10

Shanks GD, Hu Z, Waller M et al (2014) Measles epidemics of variable lethality in the early 20th century. Am J Epidemiol 179:413-422. https://doi.org/10.1093/aje/kwt282

Śmietanka K, Woźniakowski G, Kozak E et al (2016) African swine fever epidemic, Poland, 2014-2015. Emerg Infect Dis 22:1201-1207. https://doi.org/10.3201/eid2207.151708

Smit IPJ, Archibald S (2019) Herbivore culling influences spatio-temporal patterns of fire in a semiarid savanna. J Appl Ecol 56:711-721. https://doi.org/10.1111/1365-2664.13312

South African National Department of Health (2018) Health budget to prioritise NHI, HIV/AIDS treatment and new watchdog. In: Fin24. https://www.fin24.com/Budget/health-budget-toprioritise-nhi-hivaids-treatment-and-new-watchdog-20180221. Accessed 26 Sep 2018

Strassburg MA (1982) The global eradication of smallpox. Am J Infect Control 10:53-59. https:// doi.org/10.1016/0196-6553(82)90003-7 
Suthar MS, Diamond MS, Gale M (2013) West Nile virus infection and immunity. Nat Rev Microbiol 11:115-128. https://doi.org/10.1038/nrmicro2950

Swanepoel R (1995) Rabies. In: Coetzer JAW, Thomson GR, Tustin RC (eds) Infectious diseases of livestock with special reference to Southern Africa. Oxford University Press, Cape Town, pp $1123-1182$

Thompson DK (2014) Where do camels belong? The story and science of invasive species. Profile Books, London

Tilman D, Lehman C (2001) Human-caused environmental change: impacts on plant diversity and evolution. Proc Natl Acad Sci U S A 98:5433-5440. https://doi.org/10.1073/pnas.091093198

UNAIDS (2016) South Africa. http://www.unaids.org/en/regionscountries/countries/southafrica. Accessed 28 Aug 2018

Vogel SW, Heyne H (1996) Rinderpest in South Africa--100 years ago. J S Afr Vet Assoc 67:164-170

von Teichman BF, Thomson GR, Meredith CD, Nel LH (1995) Molecular epidemiology of rabies virus in South Africa: evidence for two distinct virus groups. J Gen Virol 76(1):73-82. https:// doi.org/10.1099/0022-1317-76-1-73

Vorou RM, Papavassiliou VG, Tsiodras S (2007) Emerging zoonoses and vector-borne infections affecting humans in Europe. Epidemiol Infect 135:1231-1247. https://doi.org/10.1017/ S0950268807008527

Weiss RA (2003) HIV and AIDS in relation to other pandemics. EMBO Rep 4:S10-S14. https:// doi.org/10.1038/sj.embor.embor857

White LA, Forester JD, Craft ME (2018) Disease outbreak thresholds emerge from interactions between movement behavior, landscape structure, and epidemiology. Proc Natl Acad Sci U S A 115:7374-7379. https://doi.org/10.1073/pnas.1801383115

Wolfe ND, Dunavan CP, Diamond J (2007) Origins of major human infectious diseases. Nature 447:279-283. https://doi.org/10.1038/nature05775

Woodroffe R, Sillero-Zubiri C (2012) The IUCN red list of threatened species 2012: e. T12436A16711116. https://doi.org/10.2305/IUCN.UK.2012.RLTS.T12436A16711116.en

World Health Organization (2016) Weekly epidemiological record (WER) 91:525-536, November 2016. https://apps.who.int/iris/bitstream/handle/10665/251002/WER9145.pdf?sequence $=1$

World Organisation for Animal Health (2011) No more deaths from rinderpest: OIE - World Organisation for Animal Health. http://www.oie.int/for-the-media/press-releases/detail/article/ no-more-deaths-from-rinderpest/. Accessed 27 Aug 2018

World Organisation for Animal Health (2018) World animal health information system. https:// www.oie.int/wahis_2/public/wahid.php/Wahidhome/Home. Accessed 19 Sep 2018

Open Access This chapter is licensed under the terms of the Creative Commons Attribution 4.0 International License (http://creativecommons.org/licenses/by/4.0/), which permits use, sharing, adaptation, distribution and reproduction in any medium or format, as long as you give appropriate credit to the original author(s) and the source, provide a link to the Creative Commons licence and indicate if changes were made.

The images or other third party material in this chapter are included in the chapter's Creative Commons licence, unless indicated otherwise in a credit line to the material. If material is not included in the chapter's Creative Commons licence and your intended use is not permitted by statutory regulation or exceeds the permitted use, you will need to obtain permission directly from the copyright holder.

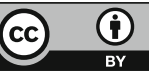

